\title{
Study on the Diversity and Use of Wild Edible Plants in Bullen District Northwest Ethiopia
}

\author{
Tariku Berihun' ${ }^{1}$ and Eyayu Molla ${ }^{2}$ \\ ${ }^{1}$ Department of Biology, Dilla University, P.O. Box 419, Dilla, Ethiopia \\ ${ }^{2}$ Department of Biology, Bahir Dar University, P.O. Box 79, Bahir Dar, Ethiopia \\ Correspondence should be addressed to Tariku Berihun; berihun.tariku@yahoo.com
}

Received 9 January 2017; Accepted 16 April 2017; Published 15 May 2017

Academic Editor: Muhammad Iqbal

Copyright (c) 2017 Tariku Berihun and Eyayu Molla. This is an open access article distributed under the Creative Commons Attribution License, which permits unrestricted use, distribution, and reproduction in any medium, provided the original work is properly cited.

\begin{abstract}
This study was designed to document the use and conservation of wild edible plants in Bullen district, northwestern Ethiopia. Data was collected through semistructured interview and focus group discussions. The collected data was analyzed through direct matrix ranking, pairwise ranking, and priority ranking methods. In this study, a total of 77 wild edible plant species were identified. Of these plants, trees account for 35.5\% followed by shrubs (31.1\%). Fruits were the most harvested parts (59.7\%) followed by leaves $(12.9 \%)$, roots and tubers $(3.8 \%)$, and rhizomes (2.5\%). These plants are consumed either raw (57.1\%) and/or cooked (17\%); most are collected by women (62.5\%) and children (20.8\%), but the participation of men is stumpy (4.2\%). According to pairwise ranking analysis, fruits of Vitex doniana and the leaves of Portulaca quadrifida are the most preferred plant species because of their sweet taste. However, some of the plants have side effects causing abdominal pain, diarrhea, and constipation. Although religion and cultural norms and values play an important role in the conservation of wild edible plants, population pressure and its associated impacts contributed much to the disappearance of these plants. Thus, community participation is the suggested solution for the conservation and sustainable use of the wild edible plants in the study area.
\end{abstract}

\section{Background and Justification}

The rural communities of developing countries depend on wild edible plants to meet their food requirements during periods of food shortage. Studies conducted by [1] indicated that the wild edible plants are mostly serving as supplementary foods in different parts of Africa. Wild edible plants are nutritionally rich [2] and can supplement especially vitamins and micronutrients [3]. These show that wild edible plants are essential components of many African diets, especially in period of seasonal food shortage.

The Ethiopian flora has approximately 6000 species of higher plants of which about $10 \%$ are endemic $[4,5]$. The country is known as the biodiversity hotspot and center of origin and diversification for a significant number of food plants and their wild relatives [6]. The wide range of climatic and edaphic conditions permitted the growing of a variety of wild food plants [7].
Some studies in Ethiopia indicated that many rural people are endowed with deep knowledge on how to use plant resources. This is particularly true with regard to the use of medicinal plants [8] and wild edible plants that are consumed at times of famine and other hardships [3]. In this regard, the elder community members are mostly the key sources of knowledge about plants [3].

The consumption of wild plants seems more common in food insecure areas of the country as compared to relatively food sufficient areas [9]. Thus, many rural people of Ethiopia usually feed on wild food plants for survival during food shortage [10]. Although wild edible plants play an important role during periods of food shortage, little attention has been given to conservation of wild edible plant species.

Available published studies on the ethnobotany of wild food plants are limited to specific area [11]. In northwestern Ethiopia, the consumption of wild food plants seems to be one of the important local survival strategies and 


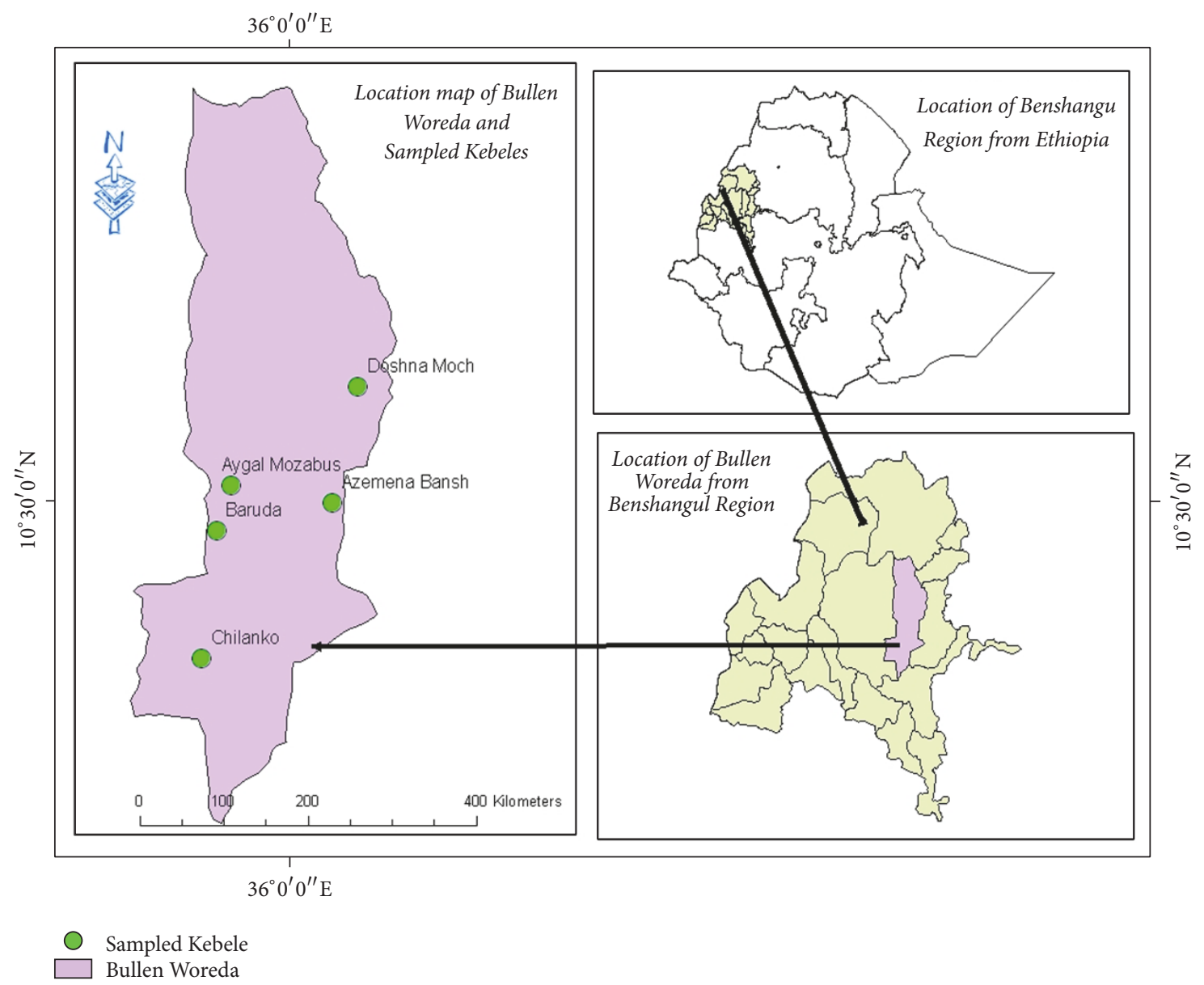

FIGURE 1: Location map of the study area (Woreda is an administrative unit almost equivalent to a district and kebele to village).

appears to have intensified due to the repeated climatic shocks hampering agricultural production and leading to food shortages [2]. In Bullen district of Benshanguel-Gumez region, the noncultivated plants provide considerable amount of supplementary food and have significant contribution to generating additional income for many households. However, there has not been sufficient research carried out about the indigenous knowledge of wild edible plants in Bullen district. Therefore, this study was designed to (1) identify and document wild edible plant species, (2) identify and record the parts of wild edible plants which are edible to humans, (3) evaluate the exploitation and conservation status of wild edible plants, and (4) assess threats on the wild edible plant species and recommend the possible management scenarios for their conservation.

\section{Materials and Methods}

2.1. Description of Study Area. Bullen district, the study area, is located in northwestern Ethiopia lying within $10^{\circ} 00^{\prime}$ to $11^{\circ} 07^{\prime} \mathrm{N}$ and $35^{\circ} 45^{\prime}$ and $36^{\circ} 07^{\prime} \mathrm{E}$ (Figure 1). The altitude varies from 900 to 2300 m.a.s.l. According to the traditional agroecological zonation of Ethiopia, $85 \%$ is Kola (lowlands, warm), 10\% Woina dega (mid-altitude moist, cool), and 5\%
Dega (highland, cool). The mean annual rainfall of the district ranges from 700 to $1000 \mathrm{~mm}$. The average annual temperature ranges from 23.5 to $35.5^{\circ} \mathrm{C}$. Diverse soil types exist in the areas, of which Acrisols and Nitisols that occur on the gentler slopes and Vertisols in the valley bottoms are the dominant ones [12].

\subsection{Methodology}

2.2.1. Reconnaissance Survey and Site Selection. A reconnaissance survey was conducted from August 10 to 25, 2010, to depict the different vegetation types, natural resource management, and indigenous knowledge associated with the use of wild edible plant species. Following the survey, focus group discussion was carried out in one of the study sites. After the discussion, five villages were systematically selected as study sites out of the total 15 villages of the district (Figure 1). The study villages were chosen based on proximity to the existing remnant forest resources and representativeness of the different agroecologies.

2.2.2. Ethnobotanical Data Collection. Seventy-two informants (40 males and 32 females) from different age groups were chosen from five villages of the study site based on the 
recommendations given from elders, Development Agents (DAs), and kebele (village) administration leaders. The ages of the informants were between 15 years and 60 years. The key informants were chosen based on traditional knowledge of wild edible plants following the suggestion made by [13]. Semistructured interviews, field observation, and focus group discussions (FGDs) were employed for data collection. Focus group discussions were employed for wild edible plants investigation to help in comparison of patterns evident among individual interviews and to reject contradictory information. Accordingly, FGDs were undertaken in groups consisting of six to eight people in five selected kebeles. Interviews were conducted in "Shinashegna, Gumuzegna, and Amharic" languages with the help of local translators.

\subsubsection{Plant Specimen Collection and Identification. Based} on the ethnobotanical information obtained from informants, specimens with their vernacular names were collected, numbered, pressed, and dried for identification. Preliminary identification was done in the field based on published guides of useful trees and shrubs of Ethiopia [4]. The identification was done mainly based on the works of [4,14-16]. All voucher specimens of the wild edible plants labeled with scientific and vernacular names were stored in Biology department herbarium, Bahir Dar University.

2.3. Data Analysis. Descriptive statistics that are percentage and frequency were used to analyze the ethnobotanical data of the reported wild edible plants and their associated indigenous knowledge. Preference ranking was computed to assess the degree of preference of wild edible fruit and leafy vegetables based on taste, edibility quality, and importance of species at different seasons. Priority ranking was employed to determine threats of wild edible plants based on their level of destructive effects. To recognize threats of wild edible plant species, values from $1-5$ were given: 1 is the least destructive threat and 5 is the most destructive threat. Use diversity ranking was carried out to identify the multipurpose use of wild edible plants which were commonly reported by the key informants.

\section{Results and Discussions}

3.1. Indigenous Knowledge (IK) Transfer and Practice. Out of the 72 respondents, 70 (93.5\%) reported that their knowledge of wild food plants was acquired through observation, imitation, and oral history, while $2(26.5 \%)$ reported that they acquired knowledge secretly from elders, when they became very old. Moreover, the respondents reported that the knowledge of wild food plants was transferred through songs, folklore, and riddles in local languages at different times especially when the people are at rest especially during the night time.

3.2. Taxonomic Diversity. A total of 77 wild edible plant species belonging to 61 genera and 39 families were recorded in the study area (Table 1). The relative high number of wild edible plants in the study area may be due to the more

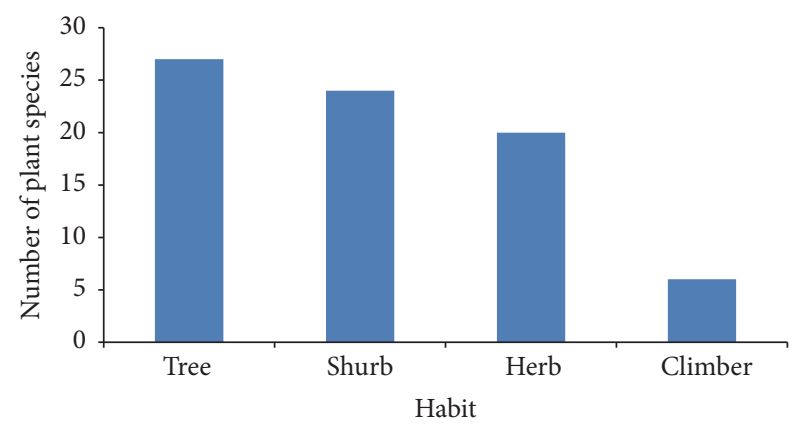

FIgURE 2: Number and habit of wild edible plants used by the local people.

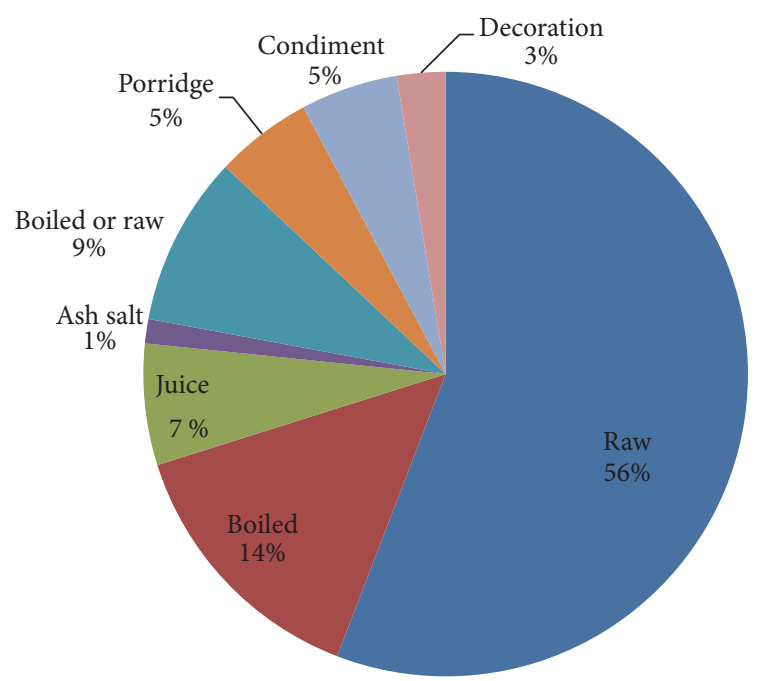

FIGURE 3: Mode of consumption.

intensive utilization of plants by the local communities and diverse agroecology. Of the reported 39 families, Tiliaceae, Euphorbiaceae, and Moraceae had the highest number of species $(5,4$, and 4$)$, respectively. But the remaining families were represented by 1 to 3 species. The reported plant species were comparable with those reported elsewhere in Ethiopia $[5,7,17]$.

3.3. Growth Forms, Parts Used, and Mode of Consumption/Preparation. The largest numbers of edible wild plant species were found to be trees, followed by herbs, shrubs, and climbers (Figure 2). This result also concurs with the works of $[17,18]$. Regarding parts used, a total of 6 edible parts were recorded. Of these, $63.6 \%$ were fruits, $20.8 \%$ leaves, and $6.5 \%$ roots and tubers, while the remaining $9.1 \%$ were flowers, nectar, stem barks, and seeds (Figure 3). This implies that more than one part of a plant species was consumed by humans. The result concurs with [19]. As regards the mode of consumption, $57.1 \%$ are consumed raw, $16.9 \%$ boiled, $6.5 \%$ in juice form, 9.1\% either raw or boiled, and $5.2 \%$ as porridge/sauce (Figure 4). 


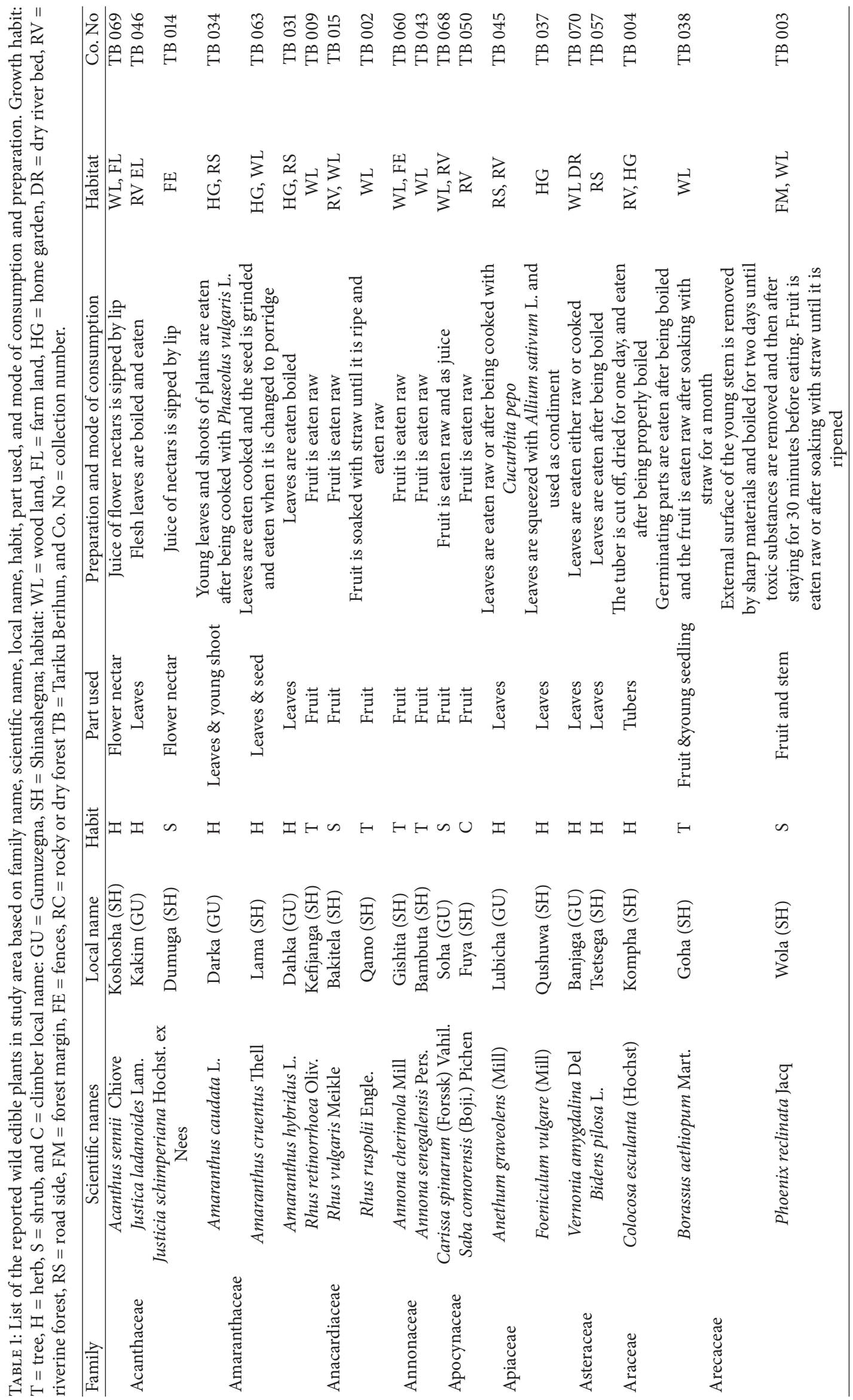




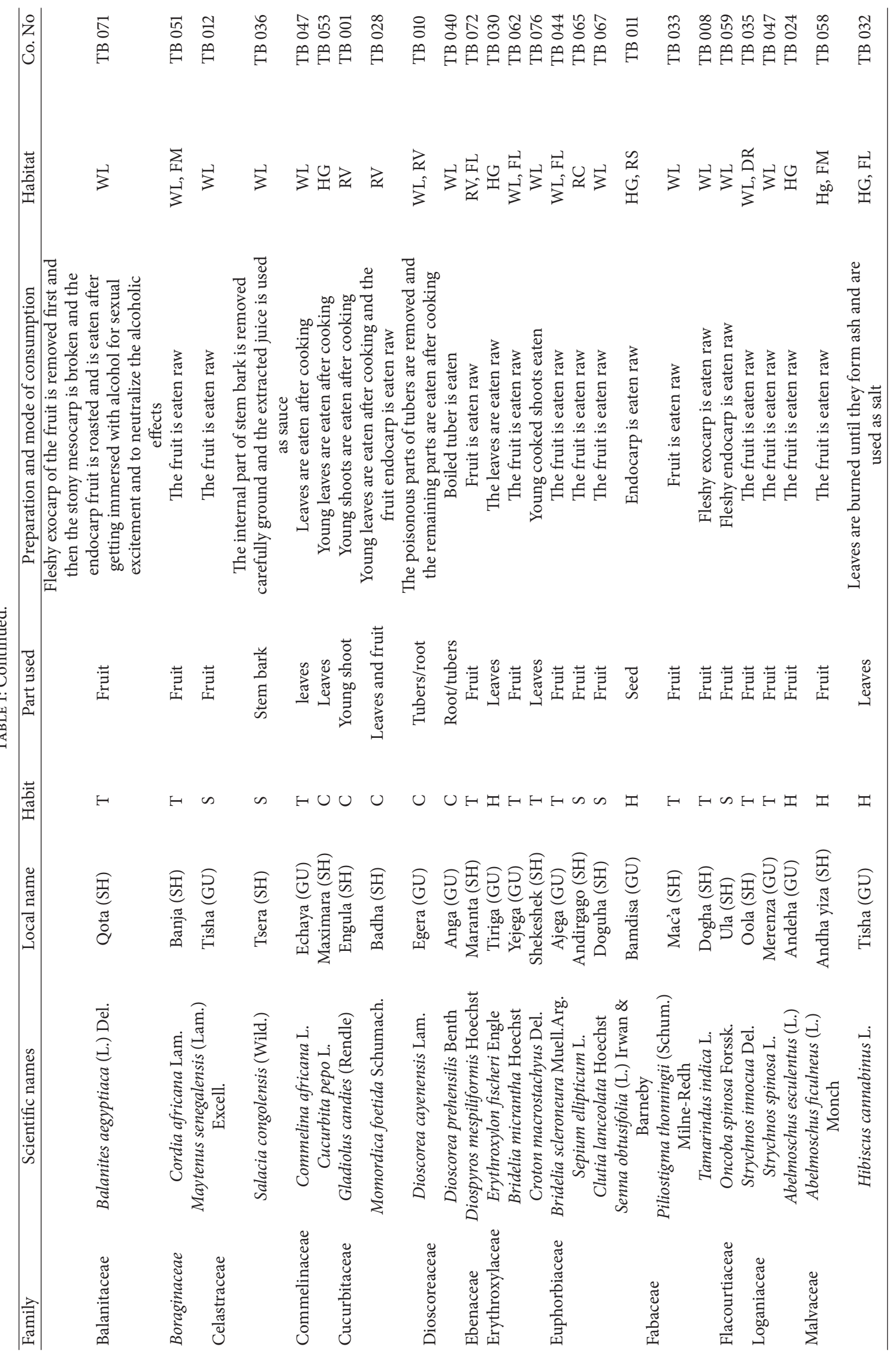




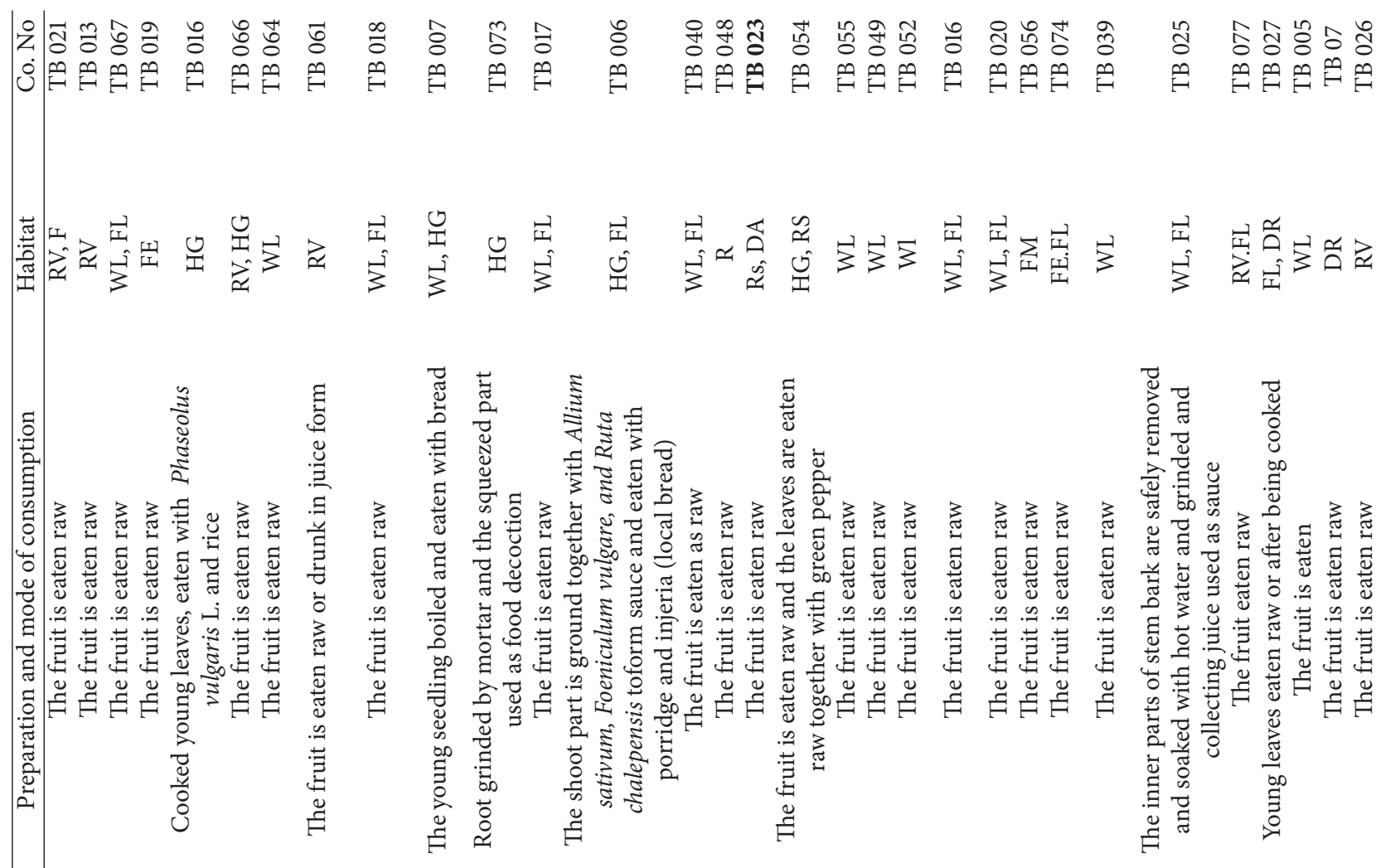

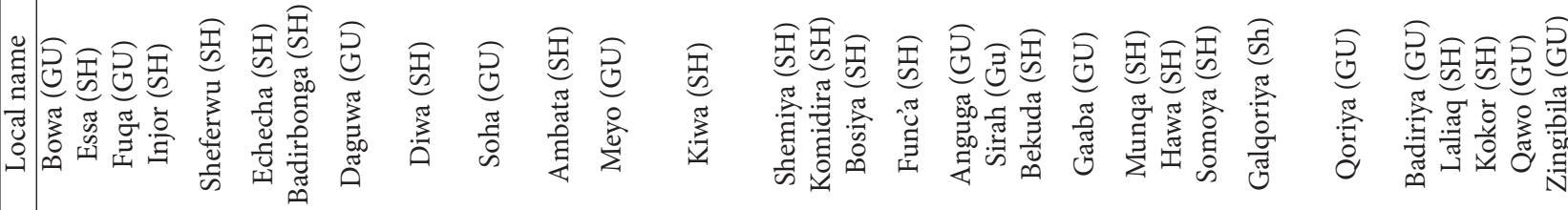

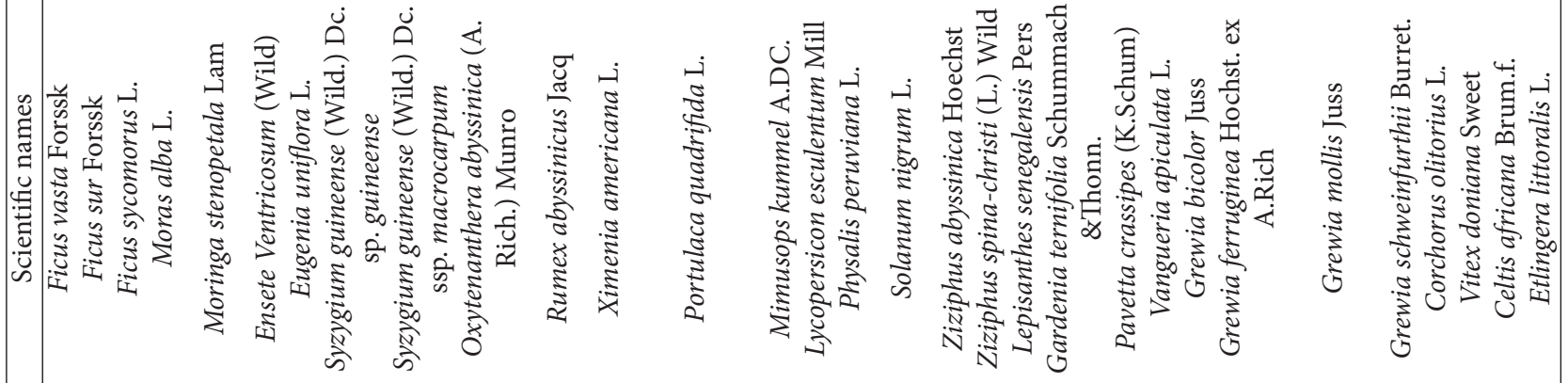

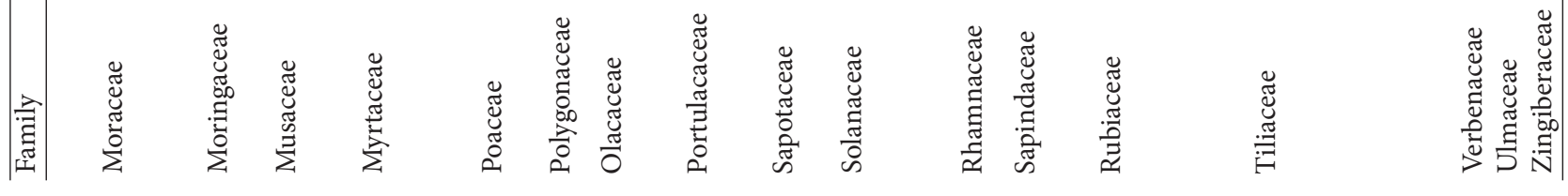


TABLE 2: Pairwise ranking based on taste of seven edible fruits in study area.

\begin{tabular}{|c|c|c|c|c|c|c|c|c|c|}
\hline \multirow{2}{*}{ Plant species } & \multicolumn{7}{|c|}{ Respondents } & \multirow{2}{*}{ Score } & \multirow{2}{*}{ Rank } \\
\hline & 1 & 2 & 3 & 4 & 5 & 6 & 7 & & \\
\hline Annona senegalensis & 4 & 5 & 2 & 3 & 4 & 5 & 2 & 25 & 2nd \\
\hline Balanites aegyptiaca & 3 & 2 & 4 & 2 & 3 & 1 & 2 & 17 & 4 th \\
\hline Vitex doniana & 5 & 4 & 2 & 3 & 5 & 5 & 4 & 28 & 1st \\
\hline Tamarindus indica & 2 & 3 & 4 & 5 & 2 & 3 & 1 & 20 & $3 \mathrm{rd}$ \\
\hline Syzygium guineense & 2 & 1 & 3 & 4 & 3 & 1 & 2 & 16 & 5 th \\
\hline Ziziphus spina-christi & 1 & 1 & 2 & 1 & 2 & 3 & 4 & 14 & 6th \\
\hline Oncoba spinosa & 2 & 3 & 3 & 2 & 2 & 1 & 1 & 13 & 7 th \\
\hline
\end{tabular}

TABLE 3: Pairwise ranking based on taste of seven green leafy vegetables in study area.

\begin{tabular}{|c|c|c|c|c|c|c|c|c|c|}
\hline \multirow{2}{*}{ Plant species } & \multicolumn{7}{|c|}{ Respondents } & \multirow{2}{*}{ Score } & \multirow{2}{*}{ Rank } \\
\hline & 1 & 2 & 3 & 4 & 5 & 6 & 7 & & \\
\hline Portulaca quadrifida & 4 & 1 & 4 & 4 & 5 & 5 & 1 & 24 & 1st \\
\hline Corchorus olitorius & 3 & 2 & 4 & 5 & 1 & 2 & 4 & 21 & 2nd \\
\hline Amaranthus hybridus & 1 & 1 & 1 & 1 & 2 & 2 & 3 & 11 & 6 th \\
\hline Solanum nigrum & 4 & 5 & 1 & 3 & 3 & 2 & 2 & 20 & $3 \mathrm{rd}$ \\
\hline Vernonia amygdalina & 2 & 2 & 1 & 1 & 1 & 3 & 2 & 12 & 5 th \\
\hline Bidens pilosa & 2 & 3 & 1 & 1 & 1 & 1 & 1 & 10 & 7 th \\
\hline Rumex abyssinica & 3 & 4 & 2 & 3 & 1 & 4 & 4 & 21 & 4 th \\
\hline
\end{tabular}

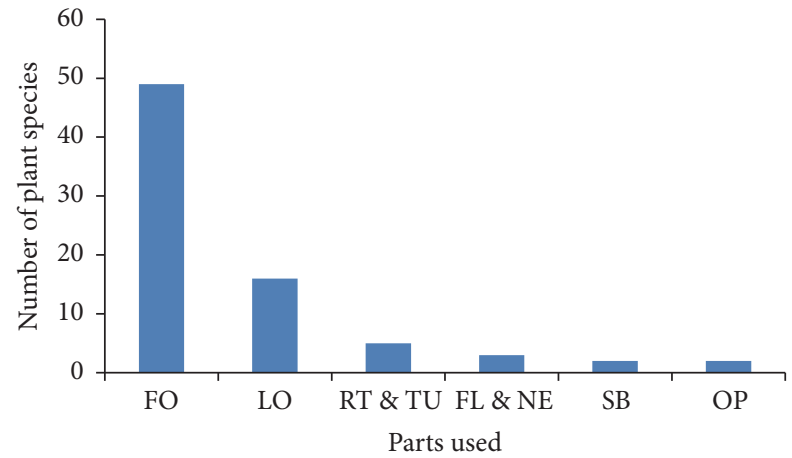

FIGURE 4: Number of wild edible plant parts used by the local people. $\mathrm{FO}=$ fruit only, Lo = leaf only, FL \& Ne = flower and nectars, SB = stem bark, RT \& TU = root and tuber, and OP = other part.

3.4. Preference of Edibility of Parts. In the study area preference of wild food plants parts varied. For example, plants consumed during famine were not consumed during normal periods. As informants reported, the roots of Dioscorea cayenensis Lam. and the young stem of Phoenix reclinata Jacq. are only consumed during times of food shortage. Moreover, the results of pairwise ranking in Table 2 indicated that the fruits of Vitex dodoniaa Sweet are the most preferred wild food fruits over the other reported wild food fruits (Table 2). This is due to them being well known by all communities. Preference of wild leafy vegetables indicates that Portulaca quadrifida L. ranks first (Table 3). This is due to their easy accessibility and palatability. These results concur with [10].
3.5. Traditional Medicinal and Other Uses of Wild Edible Plants. In the study area informants reported that of the identified plant species sixteen (20.7\%) plant species including parts such as leaves, fruit, stem bark, root, and seeds were mentioned as useful to treat one or more human health problems (Table 4). The number of these plants against the specific human ailment ranged from $1 \%$ to $18.7 \%$. Of the 16 species mentioned, the leaves and roots of Balanites aegyptiaca got priority by the local communities to relive abdominal pain. The fruit of Cordia africana is also mentioned as treatment for diarrhea; the leaves of Solanum nigrum are used to treat abdominal pain and the roots of Carissa spinarum for remedying tape worm.

Most of the plant remedies used by the people of Bullen district are obtained from herbs (37.5\%) followed by trees $(31.2 \%)$ (Table 4$)$. Data analysis showed that the majority $(20.7 \%)$ of medicinal plants in the wild are herbs and are used in the treatment of different kinds of diseases, in addition to their food value. This result indicates that people rely more on herbs and trees because they are relatively common in the area compared to shrub species. This finding agrees with the findings of $[17,20]$ in southern Wello Chefa area and Debub Omo Zone.

The most widely sought plant parts in the preparation of remedies are roots (56.2\%). The popularity of these parts has grave consequences, from both ecological point of view and the survival of the wild edible species point of view [21]. On the other hand, collecting leaves alone could not pose a lasting danger to the continuity of an individual plant compared with the collection of roots, bark, stem, or whole plant. 
TABLE 4: Traditional medicinal importance of some wild edible plants for human in the study area $(N=48)$.

\begin{tabular}{|c|c|c|c|c|c|}
\hline Scientific name & Treated health problem symptom & Part used & Habit & Number of citations & Participants cited for use (\%) \\
\hline \multirow{5}{*}{ Balanites aegyptiaca } & Abdominal pain & Leaf/root & \multirow{5}{*}{ Tree } & 9 & 18.75 \\
\hline & Malaria & Root & & 1 & 2.08 \\
\hline & A kind of dermal swelling & Root & & 1 & 2.08 \\
\hline & Hypertension & Root & & 1 & 2.08 \\
\hline & Bichawoba & Root & & 1 & 2.08 \\
\hline Bidens pilosa & Tanea pedis & Leaf & Herb & 1 & 2.08 \\
\hline Amaranthus hybridus & Tape worm & Leaf & Herb & 12 & 25 \\
\hline \multirow{3}{*}{ Carissa spinarum } & Tape worm & Root & \multirow{3}{*}{ Shrub } & 3 & 6.25 \\
\hline & Constipation & Fruit & & 1 & 2.08 \\
\hline & Gonorrhea & Fruit & & 3 & 6.25 \\
\hline \multirow{3}{*}{ Cordia africana } & Diarrhea & Fruit & \multirow{3}{*}{ Tree } & 10 & 20.8 \\
\hline & Constipation & Fruit & & 2 & 4.1 \\
\hline & Abdominal ache & Fruit & & 1 & 2.08 \\
\hline Corchorus olitorius & Diarrhea & Leaf & Herb & 1 & 2.08 \\
\hline \multirow{2}{*}{ Grewia bicolor } & Venereal disease (syphilis) & Fruit & \multirow{2}{*}{ Shrub } & 2 & 4.1 \\
\hline & Constipation & Root & & 1 & 2.08 \\
\hline \multirow{3}{*}{ Gardenia ternifolia } & Liver disease & Root & \multirow{3}{*}{ Shrub } & 1 & 2.08 \\
\hline & Abdominal ache (coli) & Root & & 2 & 4.1 \\
\hline & Abdominal distension & Root & & 1 & 2.08 \\
\hline Momordica foetida & Bronchitis & Leaf & climber & 1 & 2.08 \\
\hline Ficus sur & Ring worm & Sap & Tree & 1 & 2.08 \\
\hline \multirow{3}{*}{ Portulaca quadrifida } & Diarrhea & Aerial part & \multirow{3}{*}{ Herb } & 4 & 8.3 \\
\hline & Abdominal distension & Aerial part & & 1 & 2.08 \\
\hline & Abdominal ache coli & Aerial part & & 1 & 2.08 \\
\hline Vernonia amygdalina & Abdominal pain & Leaf & Herb & 2 & 4.1 \\
\hline \multirow{2}{*}{ Solanum nigrum } & Abdominal pain & Leaf & \multirow{2}{*}{ Herb } & 3 & 6.25 \\
\hline & Malaria & Leaf & & 1 & 2.08 \\
\hline Tamarindus indica & Abdominal pain & Fruit & Tree & 1 & 2.08 \\
\hline \multirow{3}{*}{ Ximenia americana } & Abdominal pain & Fruit & \multirow{3}{*}{ Tree } & 1 & 2.08 \\
\hline & Gastritis & Fruit & & 1 & 2.08 \\
\hline & Wound (as ointment) & Fruit & & 1 & 2.08 \\
\hline \multirow{2}{*}{ Ziziphus abyssinica } & Diarrhea & Root & \multirow{2}{*}{ Shrub } & 1 & 2.08 \\
\hline & Abdominal pan & Root & & 1 & 2.08 \\
\hline
\end{tabular}

Note. Based on growth habit, the total number of medicinal wild edible plants in the study area: herb $=6$, tree $=5$, shrub $=4$, and climber $=1$.

3.6. Multipurpose Use of Wild Edible Plants. Apart from their food and medicinal values, the reported wild edible plants are used for different purposes. Direct matrix ranking was undertaken in order to evaluate multipurpose use of tree species and their relative importance to the local people and the extent of the existing threats related to their use values (Table 5). The result of use diversity indicates that Syzygium guineense are ranked 1st because they are used for different purposes such as construction, firewood, fence, and so forth in the study area. This shows that the local people harvest the wild edible plants not only for food but mostly for construction, firewood, and furniture (Table 5).

3.7. Threats to Wild Edible Plants. Currently some of the remnant forests with large numbers of the wild edible plants in the study area are subjected to frequent deforestation by the local community. This is attributed mainly to human population pressure and its associated effects. Agricultural land expansions, wild fire, fuel wood collection, overgrazing, and overharvesting are the main reasons for the destruction of wild edible plants. Of these factors, agricultural land expansion ranks first followed by overgrazing and fuel wood collection (Table 6).

The level of threats of wild edible plants varies among the different studied villages of the district. Accordingly, informants from Aygal Mozanbus and Azemna Bansh rated agricultural land expansion as the principal threat to wild edible plant species. This is mainly due to increasing demand for arable land due to increasing human population. In the Baruda village, overgrazing uncontrolled fire setting followed by agricultural land expansion is the major factor that threatens the wild edible plants' diversity. The introduction of new grazing land due to high livestock density has possibly resulted in the overgrazing of large areas of the Baruda 
TABLE 5: Average score for direct matrix ranking of the 11 wild edible plant species on eight use criteria (use given from 0 to $4,0=$ not used, 1 = least used, 2 = good, 3 = very good, 4 = excellent).

\begin{tabular}{|c|c|c|c|c|c|c|c|c|c|c|c|c|c|}
\hline & \multicolumn{11}{|c|}{ Edible plant species and ranking ${ }^{*}$} & \multirow{2}{*}{ Total } & \multirow{2}{*}{ Rank } \\
\hline & 1 & 2 & 3 & 4 & 5 & 6 & 7 & 8 & 9 & 10 & 11 & & \\
\hline Edibility & 2 & 0 & 2 & 1 & 2 & 1 & 3 & 1 & 1 & 3 & 1 & 17 & 6th \\
\hline Medicine & 0 & 4 & 2 & 0 & 0 & 3 & 0 & 1 & 0 & 0 & 0 & 10 & 8th \\
\hline Construction/building & 1 & 3 & 4 & 3 & 3 & 4 & 3 & 3 & 3 & 2 & 0 & 29 & 1th \\
\hline Furniture & 4 & 0 & 3 & 3 & 3 & 3 & 4 & 2 & 0 & 0 & 0 & 22 & $3 r d$ \\
\hline Agricultural tools & 0 & 0 & 1 & 0 & 4 & 1 & 0 & 0 & 2 & 3 & 1 & 12 & 7th \\
\hline Fuel wood collection & 2 & 2 & 3 & 1 & 2 & 4 & 2 & 1 & 2 & 3 & 2 & 24 & 2nd \\
\hline Fodder & 2 & 1 & 1 & 4 & 3 & 3 & 1 & 2 & 0 & 4 & 0 & 21 & 4th \\
\hline Fencing & 0 & 0 & 4 & 0 & 4 & 3 & 3 & 3 & 0 & 3 & 0 & 20 & 5 th \\
\hline Total score & 11 & 10 & 20 & 12 & 21 & 22 & 16 & 13 & 8 & 18 & 4 & & \\
\hline Rank & 8 & 9 & 2 & 7 & 3 & 1 & 5 & 6 & 10 & 4 & 11 & & \\
\hline
\end{tabular}

${ }^{*} 1=$ Annona senegalensis, $2=$ Carissa spinarum, $3=$ Cordia africana, $4=$ Piliostigma thonningii, $5=$ Ficus sur, $6=$ Syzygium guineense, $7=$ Vitex doniana, $8=$ Ximenia americana, 9 = Ziziphus abyssinica, 10 = Balanites aegyptiaca, and $11=$ Ziziphus spina-christi.

TABLE 6: Priority ranking of threats to wild food plants used on their degree of destructive effects/values of 1-5 that were given: 1 is the least destructive threat and 5 is the most destructive threat.

\begin{tabular}{|c|c|c|c|c|c|c|c|c|c|c|c|c|c|c|}
\hline \multirow{2}{*}{ Factors } & \multicolumn{12}{|c|}{ Respondents of each village } & \multirow{2}{*}{ Total } & \multirow{2}{*}{ Rank } \\
\hline & A1 & $\mathrm{A} 2$ & $\mathrm{~A} 3$ & Dm1 & $\mathrm{Dm} 2$ & Dm3 & $\mathrm{B} 1$ & $\mathrm{~B} 2$ & Ch1 & Ch2 & $\mathrm{Abl}$ & $\mathrm{Ab} 2$ & & \\
\hline Agricultural land expansion & 4 & 3 & 4 & 2 & 2 & 1 & 3 & 2 & 1 & 1 & 3 & 3 & 29 & 1st \\
\hline Uncontrolled fire setting & 1 & 2 & 1 & 3 & 1 & 1 & 3 & 2 & 1 & 3 & 2 & 1 & 21 & 4 th \\
\hline Fuel wood collection & 3 & 2 & 3 & 2 & 3 & 2 & 1 & 2 & 2 & 1 & 1 & 2 & 24 & $3 \mathrm{rd}$ \\
\hline Overgrazing & 2 & 2 & 3 & 1 & 4 & 2 & 3 & 3 & 2 & 2 & 1 & 1 & 26 & 2nd \\
\hline Overharvesting & 2 & 3 & 1 & 3 & 1 & 3 & 0 & 1 & 1 & 2 & 0 & 1 & 18 & 5th \\
\hline
\end{tabular}

$\mathrm{A}=$ Aygal mozanbus; $\mathrm{Dm}=$ Doshna Moch; $\mathrm{B}=$ Bardud $\mathrm{Ch}=$ Chilanqo $\mathrm{Ab}=$ Azemina Banosh .

village. Similarly, in Doshna Moch, informants claimed fuel wood collection to be equally hazardous as overgrazing in threatening wild edible plants species. Uncontrolled fire setting was also another major threat to wild plant in Chilanqo village. It was observed that many woody species were severely affected by such fires where the tree and shrub stands decline and some are completely burned. Others are dried and collected as fire wood and the newly grown vegetative parts of woody species are further overbrowsed and trampled by overgrazing, causing considerable damage to the species. The same result was reported by [19] in Derashe and Kucha districts of southern Ethiopia, indicating that uncontrolled fire affects many woody plants including fire tolerant species when the duration of fire is too long.

\subsection{Conservation of Wild Edible Plants and Associated Knowl-} edge. Agricultural land expansion, fuel wood collection, and uncontrolled fire setting are the major threats to the conservation of wild edible plants in the study area. Despite the understanding of the local people about the importance of conserving the wild edible plants, only some in situ (in original/natural habitat) conservation methods like planting in the form of fences and protected pasture land in different worship areas (churches, mosques) and in their farm field/farm margins are being practiced in the study area. This indicates that the necessary conservation measures are not being taken in the area, and hence the wild edible plants are not free from threats.

\section{Conclusion}

The knowledge of wild food plants was transferred through songs, folklore, and riddles in local languages at different times especially when the people are at rest especially during the night time. The study revealed that all household members of the study area were involved in the collection and consumption of wild edible plant species. This helps to ensure the maintenance of indigenous knowledge associated with wild edible plant species. However, there is a decline in the consumption of some wild edible plant species that were used during periods of drought and famine such as the young seedling of Borassus aethiopum and the young stem of Phoenix reclinata which gradually lead to the fadeaway of the indigenous knowledge associated with them. The local knowledge about the nutritional composition and side effects of the wild edible plant species is very scanty and little is known about undesirable side effects such as toxicity originating from the wild edible plants. Apart from their food and medicinal value, most of the identified wild edible plant species in the study area are used by the community for other different purpose. The local people harvest the wild edible plants not only for food but also for construction, fire wood, and furniture. Particularly, wild edible plant species such as 
Syzygium guineense and Cordia africana are multipurpose plant species widely used by the local communities. Thus, this has led to a high level of threats to the wild edible plant species in the study area. In addition, many of the wild edible plants found in the study area are found to be under growing pressure, due to anthropogenic and socioeconomic factors. This has resulted in the dwindling of the species of wild edible plants and the associated indigenous knowledge.

\section{Conflicts of Interest}

The authors have not declared any conflicts of interest.

\section{Acknowledgments}

The authors are grateful to the informants and local communities of Bullen district for sharing their incredible accumulated knowledge of the wild edible plants in the field. Without their contribution, this study would have been impossible.

\section{References}

[1] P. M. Mandu, G. W. Nagugi, and C. H. S. Kabuye, Traditional Food Plants of Kenya, National Museums of Kenya, Nairobi, Kenya, 1999.

[2] A. Tesfaye, Plant diversity in western Ethiopia. Ecology, ethnobotany and conservation [Ph.D. thesis], Faculty of Mathematics and Natural Sciences, University of Osla, Norway, 2007.

[3] A. Getahun, "The role of wild plants in the native diet in Ethiopia," Agro-Ecosystems, vol. 1, pp. 45-56, 1974.

[4] B. Azene, B. Tessema, and B. Tengnas, "Useful trees and shrubs for Ethiopia identification, propagation and management for agricultural and pastoral Communiâtes Nairobi Régional Land Management Unit (RELMA)," Sida, p. 474, 1993.

[5] G. E. Tewoldebirhan, "Diversity of the Ethiopian flora," in Plant Genetic Resources of Ethiopia, J. M. M. Engles, J. G. Hawks, and M. Worde, Eds., pp. 75-81, Cambridge University Press, Cambridge, UK, 1991.

[6] A. Tesfaye, A study on the ecology and ethnobotany of noncultivated food plants and wild relatives of cultivated crops in Gambela Region, south western Ethiopia [M.S. thesis], Addis Ababa University, Addis Ababa, Ethiopia, 1997.

[7] G. Addis, K. Urga, and D. Dikasso, "Ethnobotanical study of edible wild plants in some selected districts of Ethiopia," Human Ecology, vol. 33, no. 1, pp. 83-118, 2005.

[8] D. Abebe and A. Anteneh, Medicinal Plants and Enigmatic Health Practice of Northern Ethiopia, Monograph, Addis Ababa, Ethiopia, 1993.

[9] J. Abbink, "Meen ritual, medicinal and other plants. A contribution to South-West Ethiopian ethnobotany," Journal of Ethiopian Studie, vol. 26, no. 2, pp. 1-21, 1993.

[10] T. Fentahun and H. Hager, "Exploiting, locally available resource for food and nutritional security enhancement: wild fruits diversity, potential and state of exploitation in the Amahara region of Ethiopia," Food Security, vol. 1, pp. 207-219, 2008.

[11] A. Zemede, "Conservation and use of traditional vegetables in Ethiopia," in Proceedings of the IPGRI International Workshop on Genetic Resources of Traditional Vegetables Africa, L. Guarino, Ed., p. 65, ICRAF-HQ, Nairobi, Kenya, August 1995.
[12] A. P. Mohar, The Geology of Ethiopia, Haile Sellassie I University Press, Addis Ababa, Ethiopia, 1971.

[13] G. J. Martin, Ethnobotany Method Manual, World Wide Fund for Nature (International); Champain and Haill, London, UK, 1995.

[14] S. Edwards, "Crops with wild relatives found in Ethiopia," in Plant Genetic Resources of Ethiopia, J. M. M. Engels, J. G. Hawkesand, and MelakuWerede, Eds., pp. 42-74, Cambridge University Press, Cambridge, UK, 1991.

[15] S. Edwards, D. Sebsebe, and I. Hedberg, "Flora of Ethiopia and Eriteria," in Hydrocharitaceae to Arecaceae, vol. 6, The National Herbarium, Addis Ababa, Ethiopia, 1997.

[16] S. Edwards and N. Sileshi, "Flora of Ethiopia and Eritrea," in Apiaceae to Dipsaceae, vol. 4 (2), Addis Ababa University, Addis Ababa, Ethiopia, 2003.

[17] T. Teklehaymanot and M. Giday, "Ethnobotanical study of wild edible plants of Kara and Kwego semi-pastoralist people in Lower Omo River Valley, Debub Omo Zone, SNNPR, Ethiopia," Journal of Ethnobiology and Ethnomedicine, vol. 6, article 23, 2010.

[18] A. Zemede and T. Mesfin, "Prospects for sustainable use and development of wild food plants in Ethiopia," Economic Botany, vol. 55, no. 1, pp. 47-62, 2001.

[19] B. Kebu and K. Fassil, "Ethnobotanical study of wild edible plants in Derashe and Kucha Districts, South Ethiopia," Journal of Ethnobiology and Ethnomedicine, vol. 2, no. 53, 2006.

[20] T. Bayaferes, B. Tamirat, and K. Ensermu, "An ethnobotanical study of the semi-wetland of cheffa, South Wollo, Ethiopia," in 2007. Statistical Report on Population Size and Characteristic, pp. 1-14, Addis Ababa University; Central Statistical Agency of Ethiopia (CSA), Addis Ababa, Ethiopia, 2007.

[21] A. Dawit and A. Ahadu, Medicinal Plants and Enigmatic Health Practice of North Ethiopia, Berhanina Selam Printing Enterprise, Addis Ababa, Ethiopia, 1993. 

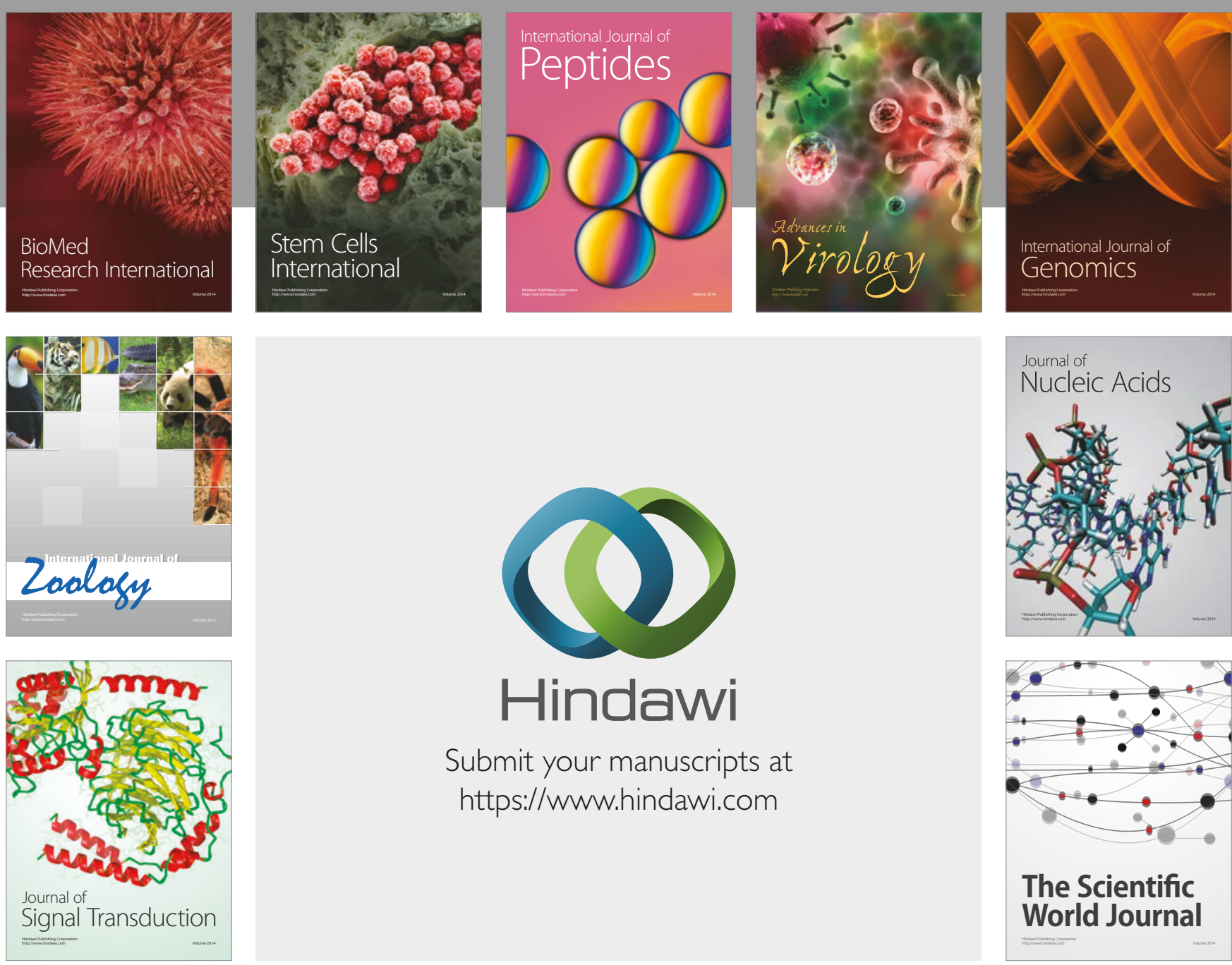

Submit your manuscripts at

https://www.hindawi.com
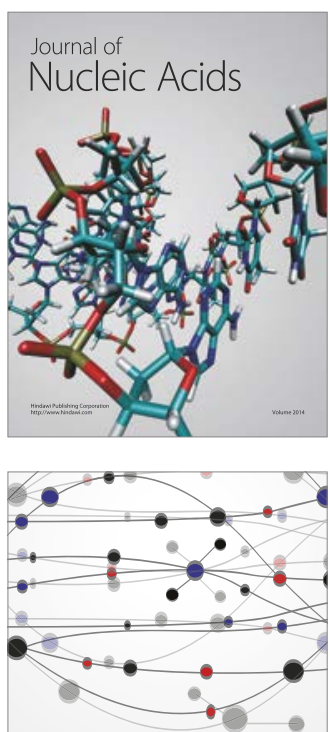

The Scientific World Journal

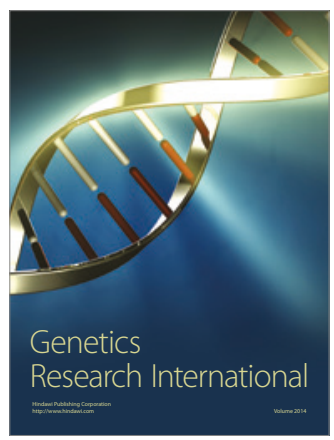

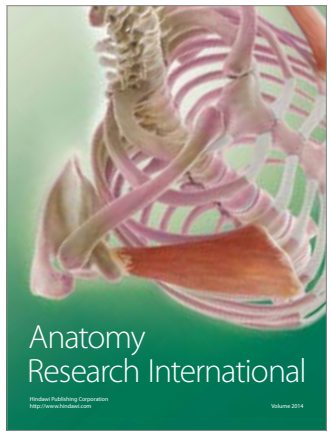

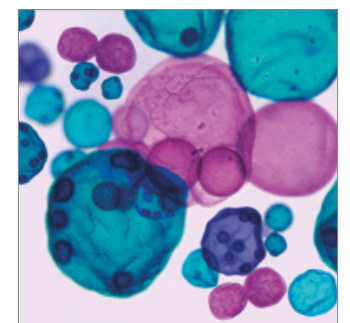

International Journal of Microbiology
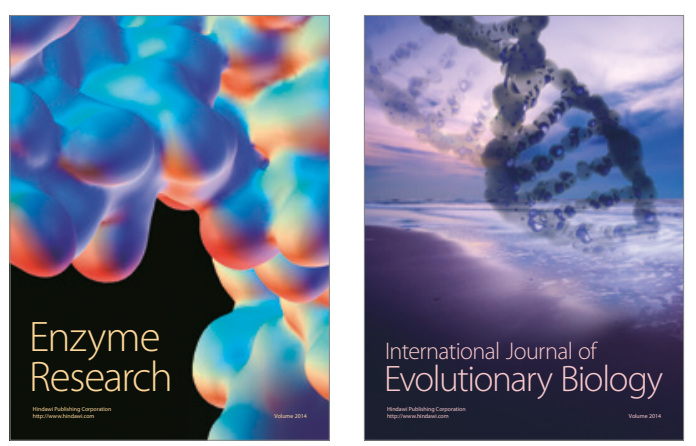
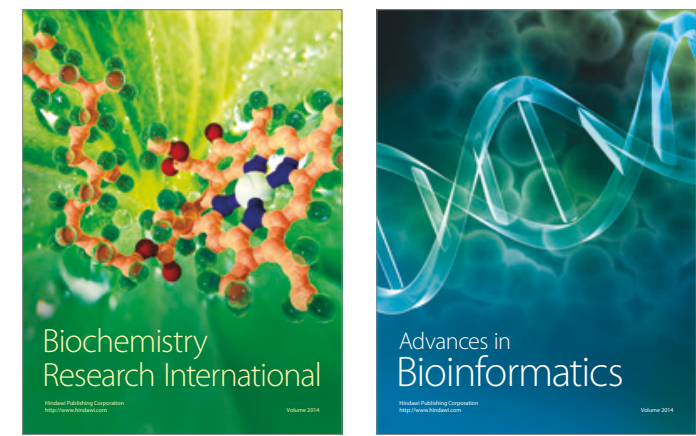

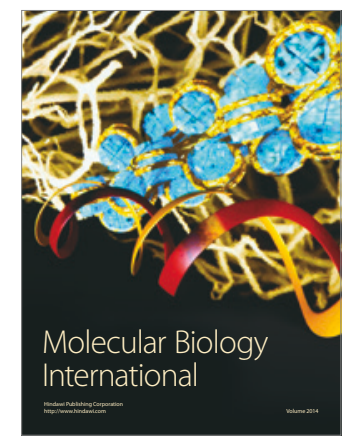

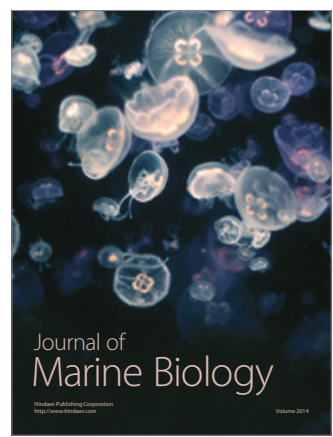

